\title{
ОПРЕДЕЛЕНИЕ ФАКТОРОВ ОТРАСЛЕВОГО РАЗВИТИЯ ГОСУДАРСТВЕННО-ЧАСТНОГО ПАРТНЕРСТВА *
}

\author{
() 2020 Хрустова Любовь Евгеньевна \\ кандидат экономических наук, старший преподаватель \\ Департамент корпоративных финансов и корпоративного управления \\ Финансовый университет при Правительстве Российской Федерации, Россия, Москва \\ E-mail: LEHrustova@fa.ru \\ (c) 2020 Пухова Марина Михайловна \\ кандидат экономических наук, доцент \\ Департамент корпоративных финансов и корпоративного управления \\ Финансовый университет при Правительстве Российской Федерации, Россия, Москва \\ E-mail: MPuhova@fa.ru
}

Практика применения государственно-частного партнерства (ГЧП) выявляет отрасли, реализация проектов в которых демонстрирует наиболее высокую результативность. Подобная тенденция позволяет говорить о существовании некоторых отраслевых характеристик, определяющих предпочтительность использования механизма ГЧП в конкретных сферах. Целью написания статьи является определение и классификация факторов отраслевого развития ГЧП.

Ключевые слова: государственно-частное партнерство, ГЧП, отраслевой аспект, проекты ГЧП, факторы ГЧП, классификация факторов

Опыт применения государственно-частного партнерства (ГЧП) доказал эффективность данной формы взаимодействия публичного и частного сектора в отдельных отраслях. Применение механизма ГЧП позволяет обеспечить необходимый для поддержания темпа роста ВВП уровень инвестиций в инфраструктуру и одновременно повысить эффективность управления бюджетными расходами.

В качестве основных преимуществ использования ГЧП в сравнении с традиционными формами финансирования социально значимых объектов выделяют увеличение финансового и ресурсного обеспечения реализации инфраструктурных проектов, сокращение публичных расходов и давления на бюджеты разных уровней, возможность оптимизации распределения рисков и обеспечения эффективности их управления, повышение качества предоставляемых обществу услуг, возможность внедрения инноваций. К числу недостатков можно отнести существование конфликта между финансовыми и социальными целями проекта в рамках ГЧП, высокие риски как для бизнеса, так и для частных партнеров, более высокую стоимость капитала, необходимость организации и осуществления сложных конкурсных процедур, наличие асимметрии информации между публичным и частным партнером [8].

Преимущества, достигаемые в процессе реализации проектов в форме ГЧП, заставляют задуматься о перспективах дальнейшего развития его применения, выявления новых отраслей, в которых ГЧП может позволить получить заметную выгоду с точки зрения государства и частного бизнеса. Проанализируем факторы, которые обеспечивают возможность реализации проектов ГЧП в различных отраслях. Для достижения указанной цели был проведен широкий анализ научных трудов отечественных и зарубежных авторов, а также практического международного опыта реализации проектов ГЧП в разрезе отдельных отраслей.

Следует отметить, что ГЧП выступает одним из механизмов финансирования и реализации, так называемых «инфраструктурных» проектов, т.е. «основных физических или организационных структур и объектов, таких как здания, дороги и системы энергоснабжения, необходимых для деятельности общества или предприятия».

* Статья подготовлена по результатам научно-исследовательской работы, выполняемой в рамках государственного задания в ФГОБУ ВО «Финансовый университет при Правительстве Российской Федерации» в 2020 году. 
При этом в трактовке Руководства по сертификации в области ГЧП под инфраструктурными могут пониматься проекты во многих сферах деятельности, таких как культура, транспорт, охрана окружающей среды, строительство, оборона, охрана правопорядка [6].

Несмотря на разнообразие отраслей, в рамках которых применяется ГЧП, к настоящему моменту сформировалась очевидная тенденция возможности обеспечения более высокого уровня эффективности реализации ГЧП в одних сферах в сравнении с другими. Так, по данным Европейского центра экспертизы ГЧП по итогам 2019 года транспортная отрасль осталась лидером как по числу реализуемых проектов (10), так и по их совокупной стоимости (более 6 миллиардов евро). Большие объемы инвестиций привлекаются также сферами ЖКХ (1,5 миллиарда евро), образования (937 миллионов евро), телекоммуникаций (826 миллионов евро) и защиты окружающей среды (388 миллионов евро). Помимо перечисленных отраслей проекты ГЧП в Европе реализуются также в сферах предоставления общественных услуг, обороны, рекреации и культуры, однако их число и объем привлекаемых инвестиций существенно ниже [10].

Успешные проекты ГЧП в настоящий момент реализуются и в странах тихоокеанского региона. В Индонезии насчитывается около 57 текущих проектов в сферах строительства объектов связи, коммунального хозяйства, социальной инфраструктуры. На Филиппинах с 2010 года было успешно профинансировано 16 ГЧП проектов на сумму 6,4 млрд. долларов, среди которых проекты по строительству аэропортов, платных автодорог, школ и университетов. В Таиланде по данным на конец 2019 года было реализовано 44 ГЧП проекта в сферах транспорта и логистики, ЖКХ, телекоммуникации, строительства [4]. Агазарян Н.В. в своей работе, ссылаясь на данные предыдущих исследований, отмечает, что в большинстве стран присутствуют отраслевые приоритеты: можно выявить одну или две сферы, в которых реализуется подавляющее большинство проектов ГЧП. Тем не менее, автор отмечает, что в последнее время все чаще появляются примеры совместной реализации проектов публичными и частными партнерами в сферах, которые ранее финансировались исключительно государством [1].

В России, по состоянию на май 2020, реализуется 2652 проекта ГЧП в коммунально- энергетической инфраструктуре, 526 - в социальной инфраструктуре, 169 - в транспортной инфраструктуре, еще 72 проекта реализуются в иных сферах.

Таким образом, можно утверждать, что совокупность определенных отраслевых особенностей реализуемых проектов может обеспечивать более высокую привлекательность проектов ГЧП для частного бизнеса. В целях выявления подобных особенностей, необходимо обозначить ключевые факторы, оказывающие влияние на эффективность ГЧП.

Анализ российских и зарубежных источников, направленных на изучение факторов, определяющих перспективы развития ГЧП в конкретных отраслях, позволил выявить недостаточную степень рассмотрения данного вопроса. Большинство существующих работ выделяют факторы, воздействующие на реализацию проектов ГЧП в равной степени во всех отраслях. Только отдельные авторы акцентируют свое внимание на особенностях конкретных проектов или упоминают наличие отраслевой специфики реализации проектов. Рассмотрим более детализировано данный аспект.

На законодательном уровне в России применяется методика расчета показателя «Уровень развития сферы государственно-частного партнерства», которая используется для оценки степени развития ГЧП в регионах. Она включает в себя показатели, характеризующие развитие институциональной среды субъекта РФ в сфере ГЧП, нормативно-правовое обеспечение сферы ГЧП и опыт реализации проектов ГЧП в субъекте. Для измерения каждого из указанных показателей используется совокупность установленных факторов. Например, развитие институциональной среды субъекта характеризуется через наличие уполномоченных органов в сфере ГЧП, специализированной структуры, ответственной за сопровождение проектов, учет механизмов ГЧП в документах целеполагания субъектов и ряд других факторов.

Применяемые факторы характеризуют в основном совокупность внешних условий, стимулирующих развитие ГЧП в рамках конкретного региона и оказывающих равное воздействие на проекты, реализуемые в различных отраслях. Факторы последней группы (опыт реализации проектов ГЧП в субъекте РФ) в определенной степени обобщают результат применения ГЧП в условиях конкретных проектов. 
Деление факторов, определяющих перспективы развития ГЧП, на внутренние и внешние широко распространено в отечественной и зарубежной научной литературе. При этом необходимо отметить, что само понимание классификации факторов на внешние и внутренние может варьировать в зависимости от подхода. Так, Муравьев Н.В. в своем исследовании выделяет внутренние и внешние драйверы развития ГЧП, в т.ч. к внутренним факторам относятся обоснованные социально-экономической ситуацией факторы в рамках страны. Следует подчеркнуть, что в отличие от подходов, представленных во многих источниках, указанные факторы имеют обозначенную отраслевую специфику. Например, внутренними драйверами развития ГЧП в России, по мнению автора, выступают необходимость привлечения частного финансирования для обновления ЖКХ, повышения привлекательности отдельных отраслей для частных инвесторов, создания стимулов для экономического развития регионов. К внешним драйверам ГЧП автор относит влияние международных организаций, давление со стороны иностранных инвесторов, интеграцию в процессы глобализации [5].

В процессе оценки институциональной среды развития ГЧП в рамках реализации кластерных проектов Бреусова А.Г. выделяет внешние факторы развития (задаваемые направлениями и нормативно-правовой базой государства) и внутренние факторы участия (определяемые реализацией федеральных направлений политики в регионе и спецификой региона как территориальной единицы) [2]. Отдельные показатели, представленные автором в процессе классификации показателей институциональной среды развития ГЧП, предполагают оценку с учетом отраслевой специфики. Так, для условий участия автором установлена необходимость оценки качества стратегии применения ГЧП в отраслевой cфере.

Вне зависимости от критериев классификации факторов развития ГЧП на внутренние и внешние, можно отметить, что большинство из них носят макроэкономический характер, с различных сторон определяют условия, создаваемые на уровне государства или регионов в целях стимулирования ГЧП. Выделение подобных факторов не объясняет причины, по которым взаимодействие публичного и частного сектора в форме ГЧП становится более эффективным в одних отраслях в сравнении с другими. Иные подходы, встречающиеся в научной литературе, также в большей степени сосредоточены на факторах, отражающих общую готовность экономической и правовой системы страны к реализации проектов ГЧП.

Авторы Савруков А.Н. и его коллеги предлагают классифицировать факторы, влияющие на развитие ГЧП в регионах, на следующие группы: политическая поддержка, нормативно-правовая база и ее характеристики, эффективная бюрократическая система, организационная поддержка проектов, методическая поддержка и формирование управленческих компетенций, макроэкономические и финансовые факторы. [7] Большинство факторов, входящих в указанные группы, также относятся к категории макроэкономических.

Авторы Е.А.Федорова, С.Е.Довженко и В.А. Гурина в своем исследовании, напротив, сосредотачиваются на изучении факторов, характеризующих специфические особенности реализации отдельных проектов ГЧП. Так, в работе авторов рассматриваются такие финансовоэкономические составляющие, влияющие на эффективность развития ГЧП в России, как срок реализации проекта, степень участия публичного партнера, форма проекта, механизм оплаты и ряд других характеристик. [9] Необходимо отметить, что авторы также уделяют внимание такому фактору как отраслевая принадлежность проекта. При этом объяснением значимости отраслевой принадлежности проекта в свою очередь выступают срок реализации проекта, а также механизмы оплаты, используемые в различных отраслях.

Рассмотрение особенности конкретных проектов в разрезе отраслевого аспекта является более информативным с точки зрения выявления факторов, обеспечивающих результативность реализации ГЧП в конкретной отрасли, в сравнении с макроэкономическим подходом. Подобный анализ позволяет выявить общие характеристики проектов, осуществляемых в конкретной сфере, что может быть использовано в процессе управления ими.

Опираясь на подход, представленный в работе Е.А.Федоровой и коллег, в рамках текущего исследования авторы рассмотрели характеристики российских проектов ГЧП по отраслям (таблица 1). Эмпирическую основу анализа составила база данных российских проектов ГЧП, 
Таблица 1. Отраслевая характеристика российских проектов ГЧП, представленных в базе проектов РОСИНФРА

\begin{tabular}{|c|c|c|c|c|c|c|c|c|c|}
\hline \multirow{2}{*}{$\begin{array}{c}\text { Характеристи- } \\
\text { ки проекта }\end{array}$} & \multicolumn{9}{|c|}{ Отраслевая принадлежность проекта * } \\
\hline & $\mathrm{C}$ & $\mathrm{O}$ & $\mathrm{T}$ & $\mathrm{CX}$ & $\Pi$ & ИС & Ж & ЖKX & Б \\
\hline $\begin{array}{l}\text { Количество } \\
\text { проектов, из } \\
\text { них: }\end{array}$ & 1084 & 9 & 397 & 46 & 192 & 72 & 14 & 4667 & 94 \\
\hline $\begin{array}{l}\text { - завершено } \\
\text { по окончании } \\
\text { срока }\end{array}$ & 89 & 1 & 11 & 3 & 9 & 4 & 5 & 421 & 3 \\
\hline $\begin{array}{l}\text { - завершено в } \\
\text { связи с рас- } \\
\text { торжением } \\
\text { соглашения }\end{array}$ & 25 & 0 & 0 & 0 & 0 & 0 & 0 & 82 & 0 \\
\hline $\begin{array}{l}\text { - завершено в } \\
\text { связи с отказом } \\
\text { от реализации }\end{array}$ & 13 & 0 & 3 & 1 & 2 & 1 & 0 & 14 & 0 \\
\hline $\begin{array}{l}\text { - в эксплуата- } \\
\text { ции }\end{array}$ & 241 & 0 & 70 & 7 & 27 & 32 & 1 & 1784 & 18 \\
\hline $\begin{array}{l}\text { Сроки реализа- } \\
\text { ции (по боль- } \\
\text { шинству } \\
\text { реализуемых } \\
\text { проектов) }\end{array}$ & $\begin{array}{c}\text { От } 10 \text { до } \\
50 \text { лет, } \\
\text { среди } \\
\text { завер- } \\
\text { шенных } \\
\text { в срок } \\
\text { преоб- } \\
\text { ладают } \\
\text { кратко- } \\
\text { срочные }\end{array}$ & $\begin{array}{c}\text { От } 3 \text { до } \\
40 \text { лет }\end{array}$ & $\begin{array}{c}\text { Как } \\
\text { кратко- } \\
\text { срочные, } \\
\text { так и } \\
\text { долго- } \\
\text { срочные }\end{array}$ & $\begin{array}{c}\text { Крат- } \\
\text { ко- и } \\
\text { средне- } \\
\text { срочные } \\
\text { проекты } \\
\text { (до } 10 \\
\text { лет) }\end{array}$ & $\begin{array}{c}\text { Средне- } \\
\text { (до } 10 \\
\text { лет) и } \\
\text { долго- } \\
\text { срочные } \\
\text { (свыше } \\
10 \text { лет) } \\
\text { проекты }\end{array}$ & $\begin{array}{c}\text { Средне- } \\
\text { срочные } \\
\text { проекты } \\
\text { (до } 10 \\
\text { лет) }\end{array}$ & $\begin{array}{c}\text { От } 1 \text { до } \\
14 \text { лет }\end{array}$ & $\begin{array}{l}\text { Средне- } \\
\text { и долго- } \\
\text { срочные } \\
\text { проекты }\end{array}$ & $\begin{array}{l}\text { Средне- } \\
\text { и долго- } \\
\text { срочные } \\
\text { проекты }\end{array}$ \\
\hline $\begin{array}{l}\text { Уровень } \\
\text { (по большин- } \\
\text { ству реализу- } \\
\text { емых проектов) }\end{array}$ & $\begin{array}{l}\text { Муници- } \\
\text { пальный } \\
\text { и регио- } \\
\text { нальный }\end{array}$ & $\begin{array}{c}\text { Феде- } \\
\text { ральный } \\
\text { и регио- } \\
\text { нальный }\end{array}$ & $\begin{array}{c}\text { Регио- } \\
\text { нальный }\end{array}$ & $\begin{array}{c}\text { Регио- } \\
\text { нальный }\end{array}$ & $\begin{array}{c}\text { Регио- } \\
\text { нальный }\end{array}$ & $\begin{array}{c}\text { Регио- } \\
\text { нальный }\end{array}$ & $\begin{array}{l}\text { Муници- } \\
\text { пальный }\end{array}$ & $\begin{array}{l}\text { Муници- } \\
\text { пальный }\end{array}$ & $\begin{array}{l}\text { Муници- } \\
\text { пальный }\end{array}$ \\
\hline $\begin{array}{l}\text { Формы } \\
\text { реализации }\end{array}$ & $\begin{array}{c}\text { Концес- } \\
\text { сионные } \\
\text { соглаше- } \\
\text { ния }\end{array}$ & $\begin{array}{c}\text { Инве- } \\
\text { стици- } \\
\text { онный } \\
\text { договор, } \\
\text { концес- } \\
\text { сионные } \\
\text { согла- } \\
\text { шения, } \\
\text { договор } \\
\text { аренды }\end{array}$ & $\begin{array}{c}\text { Концес- } \\
\text { сионные } \\
\text { соглаше- } \\
\text { ния }\end{array}$ & $\begin{array}{c}\text { Инве- } \\
\text { стици- } \\
\text { онный } \\
\text { договор, } \\
\text { концес- } \\
\text { сионные } \\
\text { согла- } \\
\text { шения, } \\
\text { согла- } \\
\text { шения о } \\
\text { сотруд- } \\
\text { ничестве }\end{array}$ & $\begin{array}{c}\text { Инве- } \\
\text { стици- } \\
\text { онные } \\
\text { соглаше- } \\
\text { ния }\end{array}$ & $\begin{array}{c}\text { Концес- } \\
\text { сионные } \\
\text { соглаше- } \\
\text { ния }\end{array}$ & $\begin{array}{c}\text { Инве- } \\
\text { стици- } \\
\text { онные } \\
\text { согла- } \\
\text { шения и } \\
\text { согла- } \\
\text { шения } \\
\text { о ГЧП/ } \\
\text { МЧП }\end{array}$ & $\begin{array}{c}\text { Концес- } \\
\text { сионные } \\
\text { соглаше- } \\
\text { ния }\end{array}$ & $\begin{array}{c}\text { Концес- } \\
\text { сионные } \\
\text { соглаше- } \\
\text { ния }\end{array}$ \\
\hline $\begin{array}{l}\text { Объем } \\
\text { инвестиций }\end{array}$ & $\begin{array}{c}\text { До } 10 \\
\text { млрд. } \\
\text { рублей }\end{array}$ & $\begin{array}{c}\text { От } 200 \\
\text { млн. до } \\
26 \text { млрд. } \\
\text { рублей }\end{array}$ & $\begin{array}{c}\text { До } 5 \\
\text { млрд. } \\
\text { рублей }\end{array}$ & $\begin{array}{c}\text { До } 8 \\
\text { млрд. } \\
\text { рублей }\end{array}$ & $\begin{array}{c}\text { До } 5 \\
\text { млрд. } \\
\text { рублей }\end{array}$ & $\begin{array}{c}\text { До } 7 \\
\text { млрд. } \\
\text { рублей }\end{array}$ & $\begin{array}{c}\text { Большой } \\
\text { разброс } \\
\text { значе- } \\
\text { ний - от } \\
2 \text { млн. до } \\
11 \text { млрд. } \\
\text { рублей }\end{array}$ & $\begin{array}{c}\text { До } 23 \\
\text { млрд. } \\
\text { рублей }\end{array}$ & $\begin{array}{l}\text { До } 500 \\
\text { млн. } \\
\text { рублей }\end{array}$ \\
\hline $\begin{array}{l}\text { *C - социальная } \\
\mathrm{O} \text { - оборона и б } \\
\mathrm{T} \text { - транспортна } \\
\mathrm{CX} \text { - сельскохоз } \\
\text { П - промышлен }\end{array}$ & $\begin{array}{l}\text { инфрастр } \\
\text { езопасност } \\
\text { я инфраст } \\
\text { яйственна } \\
\text { ная инфра }\end{array}$ & $\begin{array}{l}\text { уктура } \\
\text { ь } \\
\text { руктура } \\
\text { я инфрастю } \\
\text { структура }\end{array}$ & /ктура & & $\begin{array}{l}\text { ИС - инф } \\
\text { Ж - жили } \\
\text { ЖКХ - ко } \\
\text { Б - благо }\end{array}$ & $\begin{array}{l}\text { ормацион } \\
\text { щное стро } \\
\text { ммунальн } \\
\text { устройство }\end{array}$ & $\begin{array}{l}\text { ные систел } \\
\text { ительство } \\
\text { о-энергеть }\end{array}$ & мы & \\
\hline
\end{tabular}

Источник: составлено авторами на основе базы российских проектов ГЧП «РОСИНФРА» (режим доступа: https://rosinfra.ru/ project). 
представленная платформой «РОСИНФРА». Использованная база содержит в себе информацию о проектах, находящихся на разных стадиях реализации.

В целях формулировки выводов относительно эффективности реализации проектов ГЧП в конкретной отрасли, в рамках анализа были выделены проекты, находящиеся на эксплуатационной стадии или завершенные в связи с окончанием сроков реализации проектов. Таким образом, выдвигалось предположение о том, что успешными можно условно назвать проекты, которые находятся в процессе реализации или уже были завершены в соответствии с установленным графиком. Отдельно рассматривались также проекты, завершенные в связи с расторжением договоров или отказом от реализации. На основе представленной информации делались выводы относительно благоприятности той или иной отрасли для реализации проектов ГЧП.

Можно отметить, что в отрасли жилищнокоммунального хозяйства, в которой зарегистрировано максимальное количество проектов, почти 50\% объектов находится на эксплуатационной стадии или завершены в срок. Аналогичные показатели демонстрирует сфера информационных систем. В отрасли жилищного строительства данный показатель находится на уровне $43 \%$.

При этом в сфере социальной инфраструктуры, которая занимает второе место по числу реализуемых проектов, доля проектов ГЧП на стадии эксплуатации и завершенных по истечении срока составляет лишь 30\%. Одновременно в отрасли наблюдается наибольшая доля проектов завершенных в связи с расторжением соглашения или отказом от реализации. Таким образом, можно сделать вывод о том, что применение проектов ГЧП в сфере формирования социальной инфраструктуры сталкивается с воздействием определенных факторов, препятствующих их успешной реализации.

Важной задачей в этой связи выступает выявление этих факторов в целях дальнейшего нивелирования их влияния для стимулирования привлечения партнеров из частного сектора. Повышению интереса инвестора к проектам в социальной сфере могут препятствовать повышенная степень неопределенности относительно сроков окупаемости и прогнозирования спроса; специфика процессов ценообразования и механизмов бюджетного финансирования; сложность оценки социального эффекта.

Такие отрасли, как оборона, сельскохозяйственная инфраструктура, жилищное строительство, можно отнести к категории развивающихся, поскольку число реализуемых в них проектов на данный момент не велико. Более богатый опыт реализации проектов присутствует в сферах транспортной, промышленной инфраструктуры, информационных систем, благоустройства.

При этом в отраслях транспортной, сельскохозяйственной, промышленной инфраструктуры, информационных систем присутствует также некоторое количество проектов, реализация которых была отклонена. Можно сделать вывод о том, что несмотря на попытки, предпринимаемые в части развития ГЧП в указанных отраслях, далеко не всегда удается найти экономически обоснованное и эффективное решение поставленных задач. Особое внимание в рамках данного вопроса необходимо уделять сфере обороны и безопасности. На данный момент, в данной отрасли реализуется 8 проектов, большинство из которых находится на инвестиционной и прединвестиционной стадиях; один проект уже завершен по окончании срока. Таким образом, рассматриваемая сфера приобретает важное значение и в ближайшем будущем может стать перспективным полем для применения механизма ГЧП.

Необходимо подчеркнуть, что анализ распределения проектов по стадиям дает лишь общую характеристику тенденций реализации проектов ГЧП в отрасли и напрямую не характеризует их эффективность. Для углубленной оценки результативности проектов по отраслям важно проводить традиционную оценку эффективности, рассчитывая показатели чистой приведенной стоимости, индекса рентабельности, срока окупаемости и других критериев.

Помимо распределения проектов ГЧП по стадиям также была осуществлена оценка таких критериев, как срок, уровень, форма реализации проекта, объем привлекаемого финансирования. Анализ данных по указанным критериям, представленный в таблице 1, позволяет говорить о наличии определенных характеристик, свойственных проектам в рамках конкретной отрасли. Так, преобладающей формой реализации проектов во многих отраслях являются концессии. Однако в сфере промышленной инфраструктуры, количество проектов ГЧП в которой 
является сравнительно высоким, наблюдается тенденция преобладания инвестиционных соглашений, а в жилищном строительстве - инвестиционных соглашений и соглашений о ГЧП/ МЧП.

Аналогичным образом можно говорить о присутствии некоторой отраслевой специфики по срокам реализации проектов. В сфере жилищного строительства преобладают краткосрочные проекты, в то время как в промышленной инфраструктуре, ЖКХ и сфере благоустройства большая часть проектов является среднесрочными и долгосрочными. В некоторых отраслях наблюдаются в равной степени как краткосрочные, так и долгосрочные проекты (транспортная инфраструктура и оборона). Специфика сроков реализации проектов по отраслям должна учитываться при формировании нормативноправовой базы, определении условий контрактов, в частности, при распределении рисков и формировании системы вознаграждения частных партнеров, для стимулирования привлечения частного бизнеса к участию в проектах ГЧП.

Распределение объема инвестиций в проекты по отраслям также важно учитывать с позиции возможности применения механизма ГЧП. Сферы, реализация проектов в которых, требуют колоссальных финансовых вложений со стороны частного бизнеса, также требуют разработки более сложного, поэтапного механизма компенсации затрат частных партнеров, который позволит сбалансировать их риски и потенциальную доходность. В свою очередь, система компенсации затрат в отраслях, требующих меньшего финансирования, может быть упрощена и представлять собой стандартную схему компенсационных выплат (плата за доступность, возврат инвестиций в процессе эксплуатации, установление минимальной гарантированной доходности).

Несмотря на то, что в России подавляющее большинство проектов ГЧП реализуется на муниципальном уровне (рисунок 1), в некоторых сферах наблюдается преобладание региональных проектов. При этом в отрасли обороны и обеспечения безопасности проекты реализуются преимущественно не только на региональном, но и на федеральном уровне, что также отражает некоторую специфику отраслевой принадлежности проектов. Кроме того, необходимо отметить и тот факт, что объем финансирования, привлекаемый проектами на муниципальном уровне, в совокупности ниже, чем аналогичный показатель на федеральном и региональном уровне.

Обобщая результаты проведенного анализа, можно увидеть, что проекты ГЧП, реализуемые в различных сферах, обладают совокупностью схожих характеристик, которые необходимо учитывать в процессе взаимодействия публичного и частного партнера. Разработка организационных механизмов, методов распределения рисков и компенсации затрат представителей частного бизнеса, осуществленная с учетом рас-

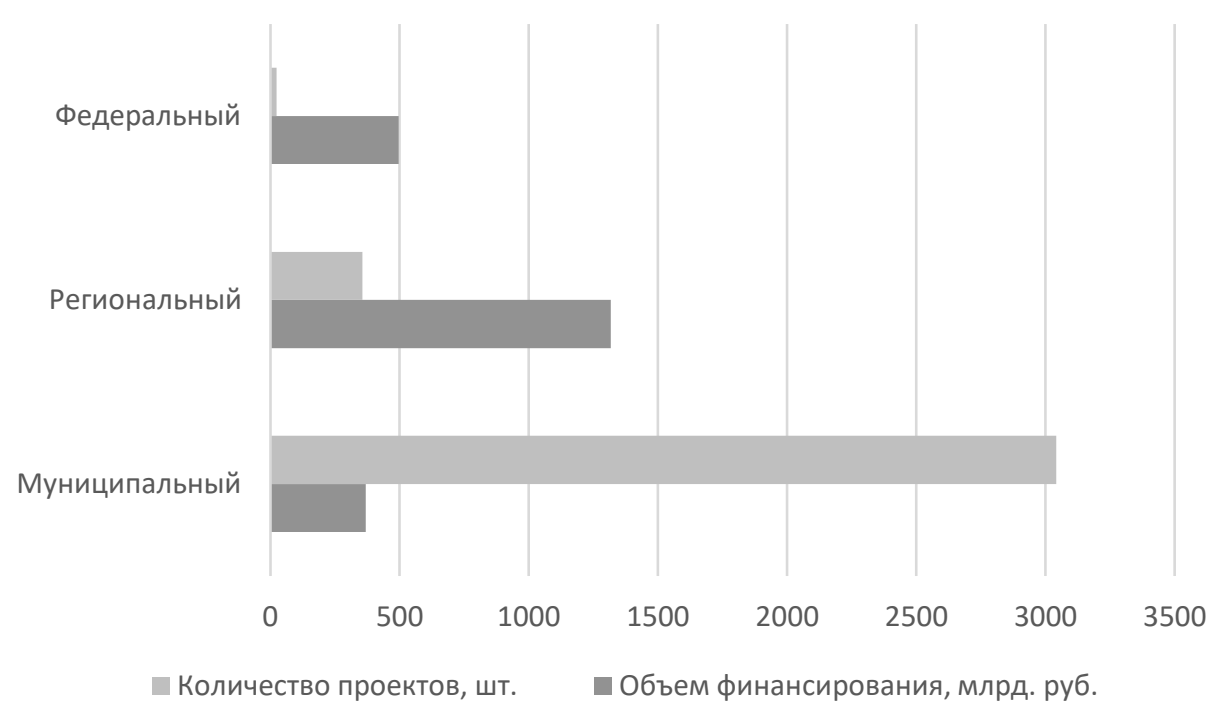

Puc. 1. Распределение российских проектов ГЧП по уровням реализации, 2019 год Источник: составлено автором на основе аналитического обзора рынка ГЧП «РОСИНФРА» (режим доступа: https://rosinfra.ru/files/analytic//document/5d5025ed02fdc0e92b70edfb6d297b4f.pdf). 
смотренных характеристик позволит стимулировать применение механизма ГЧП в отдельных отраслях и будет способствовать повышению привлекательности ГЧП для частных партнеров.

Сформулированный вывод позволяет говорить о том, что в процессе выявления факторов, определяющих отраслевое развитие ГЧП, необходимо уделять внимание не только макроэкономическим факторам, задающим условия применения рассматриваемого механизма в стране в целом, но и значимым для ГЧП отраслевым характеристикам, а также особенностям реализации отдельных проектов. Таким образом, всю совокупность факторов, определяющих развитие ГЧП в рамках отдельных отраслей, можно разделить на факторы макро-, мезо- и микроуровня.

Детализация предлагаемой классификации была осуществлена на основе масштабного обзора источников литературы за период с 1990 по 2013 годы, составленный авторами Osei-Kyei R. и Chan A. P. C. [11] Исследование ученых позволило выявить более 30 ключевых факторов, определяющих успех реализации проекта ГЧП. К числу пяти наиболее значимых были отнесены грамотное распределение рисков между публичным и частным партнером, высокоэффективное бизнес-сообщество, политическая поддержка, поддержка обществом, прозрачность конкурсных процедур.

С учетом широты эмпирической выборки, представленной в работе авторов, можно утверждать, что рассматриваемый перечень факторов является достаточно полным и достоверным. Тем не менее, он был дополнен с учетом других факторов, предлагаемых в научной литературе. Представленные в работе зарубежных авторов факторы были рассмотрены через призму предлагаемой классификации на факторы макро-, мезо- и микроуровня (таблица 2).

Необходимо отметить, что некоторые из перечисленных в таблице факторов, могут, исходя из содержания, относиться к различным категориям. Так, фактор политической поддержки может быть рассмотрен как на уровне национальной экономики в целом, так и на уровне отдельной отрасли. Аналогично, конкурентная процедура отбора может оцениваться как

Таблица 2. Классификация факторов, определяющих эффективность реализации проекта ГЧП

\begin{tabular}{|c|c|c|}
\hline \multicolumn{3}{|c|}{ Факторы, определяющие эффективность реализации проекта ГЧП } \\
\hline $\begin{array}{c}\text { Факторы макроуровня } \\
\text { (уровень национальной } \\
\text { экономики) }\end{array}$ & $\begin{array}{l}\text { Факторы мезоуровня } \\
\text { (отраслевой уровень) }\end{array}$ & $\begin{array}{c}\text { Факторы микроуровня } \\
\text { (уровень конкретного проекта) }\end{array}$ \\
\hline $\begin{array}{l}\text { - Благоприятная правовая } \\
\text { база } \\
\text { - Стабильная макроэконо- } \\
\text { мическая ситуация } \\
\text { - Политическая стабиль- } \\
\text { ность } \\
\text { - Конкурентные финансо- } \\
\text { вые предложения } \\
\text { - Зрелый и доступный } \\
\text { финансовый рынок } \\
\text { - Прозрачность конкурс- } \\
\text { ных процедур } \\
\text { - Разумная экономическая } \\
\text { политика } \\
\text { - Создание эффективного } \\
\text { уровня управления на уров- } \\
\text { не государства }\end{array}$ & $\begin{array}{l}\text { - Высокоэффективное } \\
\text { бизнес-сообщество } \\
\text { - Политическая поддержка } \\
\text { - Поддержка обществом } \\
\text { - Финансовые возможно- } \\
\text { сти частного сектора } \\
\text { - Технологические инно- } \\
\text { вации } \\
\text { - Долгосрочные спрос на } \\
\text { проект } \\
\text { - Приемлемый уровень } \\
\text { установленных тарифов } \\
\text { - Оптимальный процесс } \\
\text { утверждения заявок }\end{array}$ & $\begin{array}{l}\text { - Соответствующее распределение и разделение } \\
\text { рисков } \\
\text { - Конкурентная процедура отбора } \\
\text { - Сильная заинтересованность обеих сторон } \\
\text { - Ясность ролей и обязанностей сторон } \\
\text { - Качественное технико-экономическое обосно- } \\
\text { вание } \\
\text { - Открытое и постоянное взаимодействие меж- } \\
\text { ду сторонами } \\
\text { - Детальное планирование проекта } \\
\text { - Выбор правильного проекта } \\
\text { - Четкое описание проекта и разработка дизай- } \\
\text { на } \\
\text { - Совместимость сторон на уровне опыта и } \\
\text { квалификации } \\
\text { - Выбор правильного партнера } \\
\text { - Хорошие лидерские и предпринимательские } \\
\text { навыки } \\
\text { - Качество управления проектом } \\
\text { - Четкость постановки цели и задач } \\
\text { - Работа профессиональных консультантов } \\
\text { - Финансовая отчетность } \\
\text { - Осуществление последовательного монито- } \\
\text { ринга } \\
\text { - Надежные поставщики } \\
\text { - Влияние проекта на окружающую среду } \\
\text { - Срок, уровень, форма реализации проекта }\end{array}$ \\
\hline
\end{tabular}

Источник: составлено авторами. 
в рамках отдельного проекта, так и в качестве отраслевой характеристики (в зависимости от ведомства, организующего конкурсный отбор проектов в конкретной отрасли).

Можно также утверждать, на современном этапе развития общества, когда происходит стремительное изменение среды реализации проектов, возникают все новые и новые факторы, которые прямо или косвенно воздействуют на перспективы развития ГЧП. В настоящий момент отмечается, что с точки зрения отраслевого применения ГЧП существенной становится степень инновационности отрасли и реализуемой в ней проектов, поскольку частный бизнес демонстрирует высокую заинтересованность в участии в инновационных проектах.

Большую роль в определении перспектив отрасли с точки зрения реализации проектов ГЧП играет также степень ее подверженности влиянию кризисных факторов, что было подтверждено последними экономическими событиями. Так, по данным Национального центра ГЧП пандемия коронавируса, сопровождавшаяся девальвацией рубля, ударила более чем по 340 проектам в сфере ГЧП, большинство из которых реализуется при участии малого и среднего бизнеса. По оценкам экспертов при общей длительности ограничений около полугода совокупные потери могут составить от 25 до 30 млрд. долларов [3]. При этом выделяются отрасли в большей степени подверженные влиянию кризиса. К их числу относятся социальное обслуживание населения и бытовые услуги, здравоохранение и санитарно-курортное лечение, культура, досуг, туризм, физкультура и спорт, транспорт и транспортная инфраструктура.

В качестве факторов, влияющих на возникновение рисков при реализации ГЧП-проектов, в России в период текущего кризиса можно выделить высокую долю импортного оборудования и стройматериалов, удорожание материалов и прочих комплектующих из-за финансовых затруднений поставщиков, ослабление рубля по отношению к иностранным валютам, ускорение инфляции, приостановку строительства объектов в результате вводимых ограничений, ухудшение платежной дисциплины. Таким образом, представленный в таблице 2 перечень факторов может быть дополнен иными характеристиками, значимыми с точки зрения развития ГЧП.

Существующая практика применения механизма ГЧП позволяет выделить следующие стадии реализации проекта: принятие решения об осуществлении проекта, подготовка и подписание соглашения, реализация проекта. При этом стимулирование применения ГЧП в конкретной отрасли заключается в оказании соответствующего воздействия на факторы, определяющие развитие ГЧП, на каждой из перечисленных стадий. Рассмотрение во взаимосвязи факторов мезо- и микроуровня позволит на всех стадиях разрабатывать инструменты и механизмы, учитывающие отраслевые особенности, что является значимым моментом с точки зрения отраслевого развития ГЧП.

\section{Библиографический список}

1. Агазарян Н.В. Анализ мирового опыта применения механизма государственно-частного партнерства // Государственно-частное партнерство.-2016.- Т. 3. - № 2.- С. 151-172.

2. Бреусова А.Г. Оценка институциональной среды развития государственно-частного партнерства в рамках реализации кластерных проектов //Вестник Омского университета. Серия «Экономика».- 2018. - № . 3.С. 173-184.

3. Гальчева Анна. Эксперты оценили ущерб для государственно-частных проектов из-за вируса. / Новостной портал РБК. [Электронный ресурс]. Режим доступа: https://www.rbc.ru/economics/25/03/2020/5e79ec309a79 $474781 \mathrm{fd} 0 \mathrm{af} 3$.

4. Государственно-частное партнерство: зарубежный опыт проектного финансирования: сборник статей. Вып. 2 / кол. авторов; под ред. И.А.Никоновой, И. З. Ярыгиной.- Москва: КНОРУС, 2018. - 268 с.

5. Муравьев Н.В. Внутренние и внешние факторы развития государственно-частного партнерства в России // Известия Саратовского университета. Новая серия. Серия Экономика. Управление. Право. - 2012.- Т. 12.№ . 1.- С. 27-32.

6. Руководство APMG по сертификации в области государственно-частного партнерства (ГЧП) / ADB, EBRD, IDB, IsDB, MIF, PPIAF and WBG, 2016.- 178 c.

7. Савруков А.Н., СавруковН.Т., Козловская Э.А. К вопросу о факторах и условиях реализации проектов государственно-частного партнерства // Финансы и кредит.-2019.- Т. 25, № 12.- С. 2831-2842. 
8. Сазонов В.Е. Преимущества, недостатки и риски государственно-частного партнерства //Вестник Российского университета дружбы народов. Серия: Юридические науки.-2012.- № . 3. - С. 99-108.

9. Фёдорова E. А., Довженко С.Е., Гурина В.А. Анализ факторов, влияющих на эффективность развития государственно-частного партнерства в России //Дайджест-финансы.-2013. - № . 5.- С. 39-52.

10. Market Update. Review of the European PPP Market in 2019/ European PPP Expertise Centre. European Investment bank, 03/2020.- 14 p.

11. Osei-Kyei R., Chan A.P.C. Review of studies on the Critical Success Factors for Public-Private Partnership (PPP) projects from 1990 to 2013 // International journal of project management. - 2015.— T. 33. - № . 6. - pp. 13351346. 